\title{
Immunocytological Analysis of Potato Tuber Periderm and Changes in Pectin and Extensin Epitopes Associated with Periderm Maturation
}

\author{
Robert P. Sabba ${ }^{1}$ and Edward C. Lulai ${ }^{2}$ \\ Agricultural Research Service, U.S. Department of Agriculture, Northern Crop Sciences Laboratory, \\ Fargo, ND 58105
}

AdDitional INDEX wORDs. cell wall, homogalacturonan, pectin, phellem, phelloderm, phellogen, rhamnogalacturonan, Solanum tuberosum

\begin{abstract}
Potato (Solanum tuberosum L.) periderm forms a barrier at the surface of the tuber that protects it from infection and dehydration. Immature periderm is susceptible to excoriation (skinning injury), which results in costly storage loses and market quality defects. The periderm consists of three different cell types: phellem (skin), phellogen (cork cambium), and phelloderm (parenchyma-like cells). The phellogen serves as a lateral meristem for the periderm and is characterized by thin radial walls that are labile to fracture while the periderm is immature and the phellogen is actively dividing, thus rendering the tuber susceptible to excoriation. As the periderm matures the phellogen becomes inactive, its cell walls thicken and become resistant to fracture, and thus the tuber becomes resistant to excoriation. Little is known about the changes in cell wall polymers that are associated with tuber periderm maturation and the concurrent development of resistance to excoriation. Various changes in pectins (galacturonans and rhamnogalacturonans) and extensin may be involved in this maturational process. The objectives of this research were to compare immunolabeling of homogalacturonan (HG) epitopes to labeling of rhamnogalacturonan I (RG-I) and extensin epitopes to better understand the depositional patterns of these polymers in periderm cell walls and their involvement in tuber periderm maturation. Immunolabeling with the monoclonal antibodies JIM5 and JIM7 (recognizing a broad range of esterified HG) confirmed that HG epitopes are lacking in phellogen walls of immature periderm, but increased greatly upon maturation of the periderm. Labeling of a $(1,4)$ - $\beta$-galactan epitope found in RG-I and recognized by the monoclonal antibody LM5 was abundant in phelloderm cell walls, but sparse in most phellem cell walls. LM5 labeling was very sparse in the walls of meristematically active phellogen cells of immature periderm, but increased dramatically upon periderm maturation. Deposition of a (1,5)- $\alpha$-L-arabinan epitope found in RG-I and recognized by LM6 was abundant in phelloderm and phellogen cell walls, but was sparse in phellem cell walls. LM6 labeling of phellogen walls did not change upon periderm maturation, indicating that different RG-1 epitopes are regulated independently during maturation of the periderm. Labeling with the monoclonal antibody LM1 for an extensin epitope implied that extensin is lacking in phellem cell walls, but is abundant in phelloderm cell walls. Phellogen cell walls did not label with LM1 in immature periderm, but were abundantly labeled with LM1 in mature periderm. These immunolabeling studies identify pectin and extensin depositions as likely biochemical processes involved in the thickening and related strengthening of phellogen walls upon inactivation of the phellogen layer as a lateral meristem and maturation of the periderm in potato tuber. These results provide unique and new insight into the identities of some of the biological processes that may be targeted in the development of new technologies to enhance resistance to tuber skinning injury for improved harvest, handling and storage properties.
\end{abstract}

Potato periderm maturation is an important physiological process that reduces tuber susceptibility to excoriation of the skin. Maturation of tuber periderm is often incomplete at harvest and causes the tuber to be susceptible to skinning injury (Lulai, 2002). Periderm excoriation renders potatoes vulnerable to dehydration, infection, and development of physiological defects during storage, and results in millions of dollars of losses to producers in the United States every year. Potato periderm is made up of three cell types: the phellem (cork), the phellogen (cork cambium), and the phelloderm (Fig. $1 \mathrm{~A}$ and B). The phellem and phelloderm cells are derived from periclinal divisions of the phellogen layer, which functions as a lateral meristem (Artschwager, 1924; Peterson and

Received for publication 11 Mar. 2005. Accepted for publication 13 May 2005 The authors thank J.P. Knox for the generous gift of JIM5, JIM7, and LM1 antibodies, as well as T.P. Freeman and K.C. Vaughn for invaluable technical advice. Mention of company or trade name does not imply endorsement by the U.S. Dept. of Agriculture over others not named.

${ }^{1}$ Current address: Univ. of Wisconsin-Madison, Dept. of Horticulture, 1575 Linden Drive, Madison, WI 53706.

${ }^{2}$ To whom reprint requests should be addressed. Email address: lulaie@fargo. ars.usda.gov
Barker, 1979). Cells external to the phellogen layer (i.e., in the direction of the tuber surface) differentiate into phellem cells, which suberize during development to form the protective skin of the tuber (Lulai, 2001). Cells internal to the phellogen layer (i.e., in the direction of the tuber interior) differentiate into phelloderm cells. During development of the periderm, phellogen cells are meristematically active and are characterized by thin radial walls which can fracture easily leading to susceptibility to periderm excoriation (Lulai, 2002). These cell walls strengthen/thicken after periderm development is complete and the phellogen cells become permanently meristematically inactive (Lulai and Freeman, 2001). Despite the importance of this system agriculturally and as a model for the irreversible changes that take place in a lateral meristem, the biochemical processes responsible for phellogen cell wall strengthening/thickening during the maturation of potato periderm are poorly understood.

The dicot plant cell wall is currently viewed as consisting of three separate, but interrelated domains: the cellulose-xyloglucan backbone, the pectin framework, and a network of structural proteins (Schindler, 1998). Pectins are a group of complex polysaccharides containing D-galacturonic acid (Ridley et al., 2001; 
Thakur et al., 1997). The simplest of these is homogalacturonan (HG), which is a linear homopolymer of [1-4] $\alpha$-D-galactopyranosyluronic acid, often methyl-esterified at its free carboxyl groups. Un-esterified blocks of HG can form gels in the presence of calcium ions (calcium pectate) which form ionic bridges between adjacent pectin strands, thereby reducing their flexibility and strengthening cell walls (Thakur et al., 1997). When HG is synthesized in the Golgi apparatus, the polymer is normally methyl-esterified, which prevents it from forming calcium pectate. After HG is placed in the cell wall, pectin methyl-esterases (PMEs) may de-esterify HG blocks (which allows the formation of calcium gels and increases cell wall rigidity) as reported in several systems other than potato (Goldberg et al., 1996).

Another common pectin is rhamnogalacturonan I (RG-I), which consists of $(1,2)-\alpha$-L-rhamnose- $(1,4)-\alpha$-D-galacturonic acid repeats with neutral and acidic oligosaccharide side chains dominated by galactose and arabinan (Willats et al., 2001). The structure and occurrence of RG-I is highly variable compared with other types of pectin and is believed to be covalently attached to HG by glycosidic bonds. While RG-I is ubiquitous in plant cell walls, its functions are mostly unknown (Ridley et al., 2001; Willats et al., 2001). Recent evidence indicates that RG-I in potato is abundant in $(1,4)-\beta$-galactan side chains and $(1,5)$ - $\alpha$-L-arabinan side chains with $(1,4)$ - $\beta$-galactan extensions (Obro et al., 2004).

Plant cell walls contain a number of structural glycoproteins made up of simple repeating subunits. The first to be described were the hydroxyproline-rich glycoproteins (HRGPs) (Cassab, 1998). The best studied of the HRGPs is the extensin family, which is characterized by Ser-Hyp-Hyp-Hyp-Hyp repeats and is about two-thirds polysaccharide by weight (Cooper et al., 1987; Wilson and Fry, 1986).

Previously, we demonstrated that phellogen radial cell wall thickening during periderm maturation is accompanied by increases in ruthenium red staining (Sabba and Lulai, 2002) and JIM5 and JIM7 labeling (Sabba and Lulai, 2004) characteristic of HG. In the current paper we further employ immunolabeling techniques to compare the distribution of HG epitopes with RG-I and extensin cell wall epitopes within immature and mature potato tuber periderm. Results are then used to assess the involvement of the associated cell wall polymers in tuber periderm maturation which is associated with excoriation resistance.

\section{Material and Methods}

Preparation of Sample material. Tubers of S. tuberosum L. (cv. Russet Burbank) harvested early in the season (Aug. 2000 and 2001) exhibited immature periderm which excoriated readily. Tubers harvested late in the season (Sept. 2000 and 2001) or stored for 1 month after harvest had mature periderm, which did not excoriate readily. Tissue blocks including periderm were cut from the tubers and fixed in $2.5 \%$ glutaraldehyde in phosphate buffer ( $\mathrm{pH}$ 7.3). Fixed periderm blocks were washed in phosphate buffer ( $\mathrm{pH}$ 7.3), hand sectioned with a razor blade, and dehydrated through a graded ethanol series (25\% to $100 \%)$. Dehydrated samples were embedded in L.R. White resin (Polysciences, Warrington, Pa.) over a period of 1 week and polymerized in plastic BEEM capsules (Ted Pella, Redding, Calif.) according to manufacturer's instructions.

IMMUNOLABELING AND SILVER ENHANCEMENT. L.R. White embedded periderm samples were sectioned with an ultramicrotome (purple reflectance, 150-200 $\mathrm{nm}$ ) and parallel sections (i.e., sec- tions obtained from the same tissue block and proximity) were placed onto silane-treated glass slides (Sigma Chemical Co., St. Louis). One set of sections were stained with $0.1 \%$ toluidine blue $\mathrm{O}$ (TBO) (Sigma Chemical Co.) to distinguish and identify all cell walls present in the sections. The other sections were blocked with $2 \%$ bovine serum albumin (BSA) in phosphate-buffered saline (PBS) for $1 \mathrm{~h}$, then incubated with a monoclonal antibody diluted with $1 \%$ BSA in PBS for either $3 \mathrm{~h}$ at room temperature, or overnight at $4{ }^{\circ} \mathrm{C}$. The antibodies used were either JIM5 diluted 1:200 (preferentially binds to $30 \%$ to $50 \%$ esterified pectin), JIM7 diluted 1:100 (preferentially binds to $30 \%$ to $90 \%$ esterified pectin), LM5 diluted 1:200 [specific for $(1 \rightarrow 4)-\beta$-galactan], LM6 diluted 1:50 [specific for $(1 \rightarrow 5)-\alpha-L$-arabinan], or LM1 diluted 1:50 (preferentially binds to extensin). JIM5, JIM7, and LM1 antibodies were gifts of J.P. Knox, U. of Leeds, U.K. (Knox et al., 1990; Smallwood et al., 1995). LM5 and LM6 antibodies were purchased from Plant Probes, Leeds, U.K. One set of sections were incubated in 1\% BSA in PBS instead of diluted antibody, to serve as a negative control. Samples were washed $4 \times$ in $1 \%$ BSA in PBS and incubated in goat ant-rat IgG coupled to $5 \mathrm{~nm}$ colloidal gold (EY laboratories, San Mateo, Calif.) for 1 h. Samples were washed $4 \times$ with $1 \%$ BSA in PBS and $5 \times$ with water. Immunolabeling was silver-enhanced with Intense MSilver Enhancement kit (Amersham Pharmacia Biotech, Piscataway, N.J.) according to the manufacturer's instructions and digital images were taken with a Zeiss AxioCam at $400 \times$ magnification (Carl Zeiss, Thornwood, N.Y.). All experiments were repeated at least three times with different samples. Sections that were not incubated in a primary antibody did not exhibit labeling after silver enhancement.

\section{Results}

Toluidine Blue O staining. Staining with TBO clearly differentiates between the suberized phellem layers and the phellogen and phelloderm layers interior to the phellem in both immature and mature periderm (Figs. $1 \mathrm{~A}$ and B, $2 \mathrm{~A}$ and B, and $3 \mathrm{~A}$ and $\mathrm{B}$ ). The suberized phellem layers stained orthochromatically (blue) while the phellogen and phelloderm walls stained metachromatically (violet). A striking characteristic of the phellogen radial walls is that they are thin and fragile in immature periderm, while they are thicker and more robust in mature periderm. TBO stained parallel sections are shown for all immunolabeled sections as a standard comparison.

JIM5 IMMUNOLABELING. The monoclonal antibody JIM5 preferentially recognizes $30 \%$ to $50 \%$ methyl-esterified HG. The phelloderm cell walls of both immature and mature periderm labeled abundantly with JIM5, as did the most interior phellem layer (Fig. 1C, 1D). The walls of the innermost and outermost phellem cells labeled moderately, but the majority of the phellem cell walls labeled very sparsely. Labeling of phellogen and phelloderm cell walls was most abundant at three-way cell junctions, while labeling of phellem cell walls tended to exclude the middle lamella and three-way cell junctions. In immature periderm, the radial walls of the phellogen cells were sparsely labeled with JIM5 (Fig. 1C). JIM5 labeling was more abundant in the thickened phellogen radial walls of mature periderm, indicating an increase of this epitope in these walls upon maturation (Fig. 1D).

JIM7 IMMUNOLABELING. The monoclonal antibody JIM7 recognizes a broad range of esterified HG. In both immature and mature periderm, the walls of the phelloderm and all of the phellem layers labeled with JIM7 (Fig. 1E, 1F). Labeling was 
even throughout the cell walls of phellogen and phelloderm cells, but was excluded from the middle lamella and three-way cell junctions of phellem cells. JIM7 sparsely labeled the phellogen radial walls of immature periderm (Fig. 1E). Labeling with JIM7 was abundant in the thickened phellogen radial walls of mature periderm, however, indicating an increase in this HG epitope in these walls upon maturation (Fig. 1F).

LM5 ImmunOLABELING. The monoclonal antibody LM5 specifically recognizes a $\beta$-galactan tetrasaccharide epitope common to RG-I. The phelloderm cell walls of both immature and mature periderm labeled abundantly with LM5, as did the cortical parenchyma interior to the phelloderm (Fig. $2 \mathrm{C}$ and D). Labeling was less abundant in the three-way cell junctions and middle lamella. The phellem did not label with LM5, except for very sparse labeling of the most interior layer adjacent to the phellogen. In immature periderm, the radial and upper tangential walls of the phellogen cells labeled very sparsely if at all (Fig. 2C). LM5 labeling was much more abundant in the thickened phellogen walls of mature periderm, indicating an increase in the RG-I galactan epitope in these walls upon maturation (Fig. 2D). Labeling of the walls of the interior most phellem cells was also more abundant in mature periderm. There was a reduction in labeling of short segments ( 4 to $5 \mathrm{~nm}$ ) of cortical parenchyma walls that most likely represent pit-fields (Fig. 2C).

LM6 IMMUNOLABELING. The monoclonal antibody LM6 specifically recognizes an $\alpha$-L-arabinan pentasaccharide epitope common to RG-I. For immature periderm, LM6 labeling was abundant in the phelloderm and the phellogen, but labeling of phellem cell walls was sparse (Fig. 2E). Labeling tended to be excluded from the middle lamella of the phellem and from the three-way cell junctions of the phelloderm and cortical parenchyma cells interior to the periderm. Labeling in mature periderm was similarly abundant for phellogen and phelloderm cell walls (Fig. 2F). There was no difference in labeling of the phellogen radial walls between immature and mature periderm, except for a lack of labeling in the expanded middle lamella between phellogen cells in mature periderm. Phellem walls were barely labeled in mature periderm (Fig. 2F). Similar to LM5 labeling, LM6 labeling was reduced in short (4 to $5 \mathrm{~nm}$ ) segments of cortical parenchyma cell walls. These segments most likely represent pit fields.

LM1 IMMUNOLABELING. The monoclonal antibody LM1 recognizes an extensin epitope. LM1 labeling was abundant in the phelloderm of both mature and immature periderm, but labeling of phellem cell walls was very sparse or nonexistent (Fig. 3C, 3D). Labeling tended to be most abundant at three-way cell junctions. The upper tangential and radial walls of phellogen cells in the immature periderm labeled sparsely for extensin (Fig. 3C). Labeling with LM1 was much more abundant in both the phellogen radial and tangential walls of mature periderm, indicating an increase in the LM1 epitope in these walls upon maturation of the periderm (Fig. 3D).

\section{Discussion}

TBO staining was shown previously to provide a simple method to distinguish between the phellem (which stained blue or orthochromatically) and the phellogen layer (which stained violet or metachromatically) of both immature and mature potato periderm (Sabba and Lulai, 2004). The difference in staining may be due to the presence of suberin polymers in the phellem cell walls, which are absent from the walls of phellogen and phelloderm cells (Lulai, 2001). In immature periderm, the phel- logen cell walls are very thin, especially the radial walls, but after periderm maturation, the phellogen walls are elongated and feature thickened tangential and radial walls. This thickening of phellogen radial walls in mature periderm was shown earlier by electron microscopy to be responsible for strengthening of these walls and making them resistant to fracture (Lulai and Freeman, 2001). Strengthened phellogen radial walls are associated with maturation of the tuber periderm and development of resistance to excoriation (Lulai, 2002). Electron microscopy (EM) studies of immature tuber periderm have been hampered by the fragile nature of phellogen cell walls and the subsequent fracture of these walls during tissue preparation (Lulai and Freeman, 2001). The light microscopy techniques employed in this study provided better tissue orientation than EM techniques and reduced the frequency of phellogen cell wall fracture during tissue preparation, thus providing images of intact immature periderm that were otherwise extremely difficult to obtain.

The monoclonal antibody JIM5 binds to an epitope present in relatively unesterified HG polymers (Knox et al., 1990; Willats et al., 2000a). Recently it was reported that JIM5 recognizes epitopes with four or more contiguous unesterified galacturonan residues with adjacent or flanking methyl-esterified residues (Clausen et al., 2003). JIM5 does not bind to acetylated HG from sugar beet (Beta vulgaris L.), or to the rhamnogalacturonan pectins (Willats et al., 2000a). Similar to our previous report, JIM5 labeled three-way cell junctions in the phelloderm particularly densely, and labeled all but the most interior phellem cells sparsely (Sabba and Lulai, 2004). It is unlikely that the labeling of primary phellem walls would be blocked by suberin polyphenolics or polyaliphatics because these polymers are discrete and spatially separate domains from the primary cell wall; a fact further illustrated by the suberization of existing primary cell walls in the closing layer of wound-healing tuber parenchyma (Lulai, 2001; Lulai and Freeman, 2001; Lulai and Morgan, 1992). Thus, the cut surface of the primary cell wall is expected to be fully exposed to immunolabeling treatment after sectioning. JIM5 labeling of phellogen radial walls was sparse in immature periderm, but was more abundant in mature periderm, indicating an increase in the amount of this HG epitope in phellogen radial walls upon maturation of the periderm and meristematic inactivation of the phellogen. An increase in low ester pectin would allow the formation of calcium pectate which would be expected to strengthen the phellogen radial walls and stabilize the middle lamella between adjacent cells once the phellogen was no longer actively dividing.

The monoclonal antibody JIM7 binds to an epitope present in moderately to highly esterified HG (Knox et al., 1990; Willats et al., 2000a). Recently it was reported that JIM7 recognizes epitopes with either three or more methyl-esterified galacturonan residues, or alternating methyl esterified residues, all with adjacent or flanking unesterified residues (Clausen et al., 2003). JIM7 does not bind to acetylated $\mathrm{HG}$ from sugar beet, or to the rhamnogalacturonan pectins, but unlike JIM5, JIM7 binds to highly esterified HG (Willats et al., 2000a). The more evenly distributed JIM7 labeling was dense in phelloderm cell walls as well as phellem walls as we reported recently (Sabba and Lulai, 2004). These results imply that phellem walls do indeed contain $\mathrm{HG}$, but that most of it is methyl-esterified. Consistent with JIM5 labeling, phellogen radial walls in immature periderm labeled only sparsely with JIM7. In mature periderm, JIM7 labeling of phellogen radial walls was greatly increased compared to immature periderm, confirming that $\mathrm{HG}$ is increased in the thickened phellogen radial walls of mature periderm. In comparison, the walls of young actively 


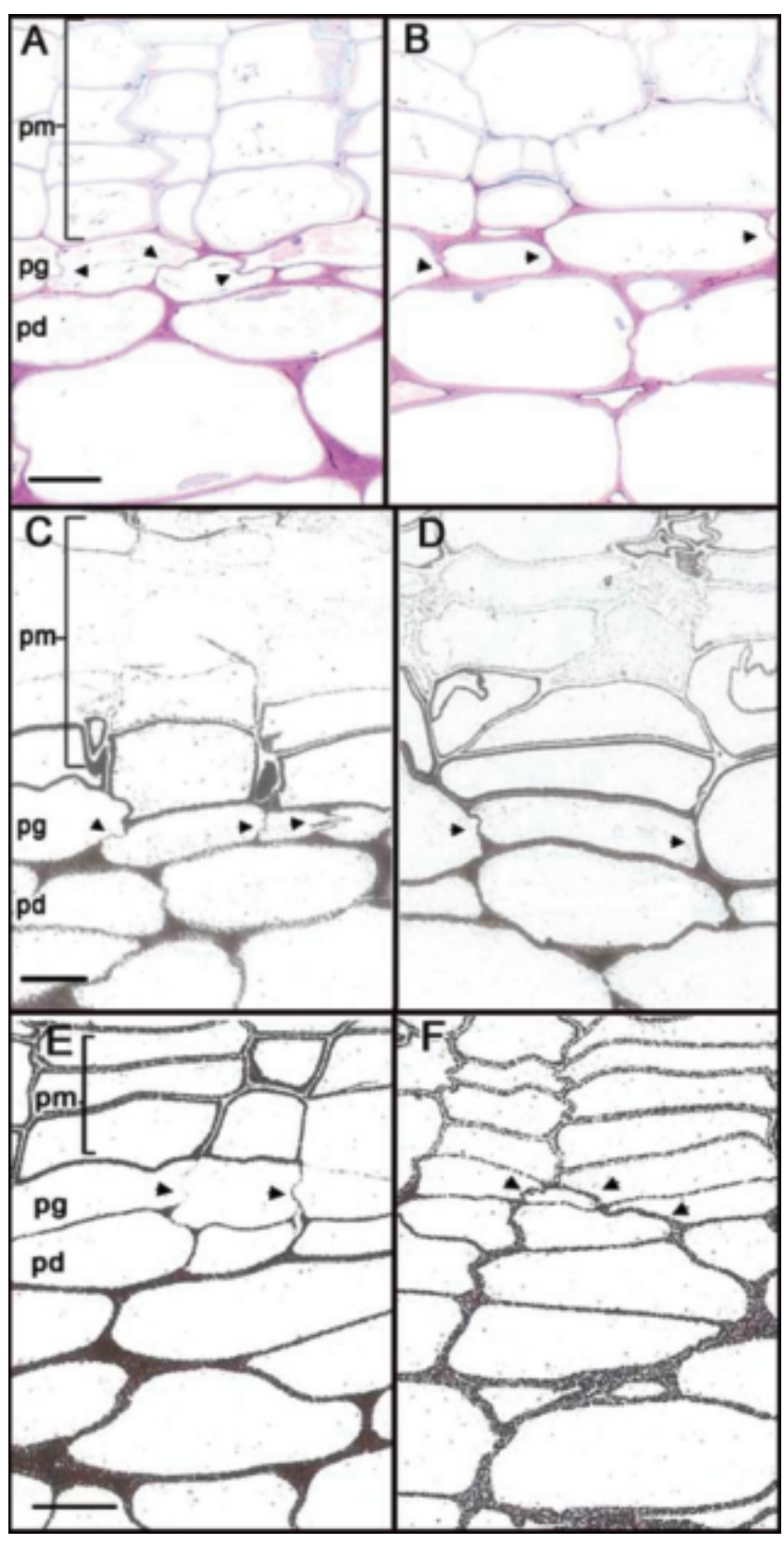

Fig. 1. (Above) Immunolabeling of homogalacturonan $(\mathrm{HG})$ epitopes in potato periderm parallel sections. Toluidine blue O stained immature (A) and mature (B) periderm. Note that phellogen radial walls (indicated by arrowheads) are thicker in mature periderm, than in immature periderm. JIM5 labeling of immature (C) and mature (D) potato periderm for an epitope common to relatively unesterified HG. JIM7 labeling of immature (E) and mature (F) periderm for an epitope common to a wide range of esterified HG. Note the increase in JIM5 and JIM7 labeling of phellogen radial walls (indicated by arrowheads) in mature periderm. Bar $=20 \mu \mathrm{m}, \mathrm{pm}=$ phellem, $\mathrm{pg}=$ phellogen, $\mathrm{pd}=$ phelloderm .

Fig. 2. (Top right) Immunolabeling of rhamnogalacturonan I epitopes in potato periderm parallel sections. Toluidine blue $\mathrm{O}$ stained immature (A) and mature (B) periderm. LM5 labeling of (C) immature and (D) mature periderm for a $(1,4)-\beta$-galactan epitope. Note the increase in labeling of phellogen radial walls (indicated by arrowheads) in mature periderm. LM6 labeling of (E) immature and $(\mathbf{F})$ mature periderm for a $(1,5)-\alpha$-L-arabinan epitope. There is no discernable difference in LM6 labeling of phellogen radial walls (indicated by arrowheads) between immature and mature periderm. Labeling for both epitopes is reduced in pit fields (indicated by asterisks). Bar $=20 \mu \mathrm{m}, \mathrm{pm}=$ phellem, $\mathrm{pg}=$ phellogen, $\mathrm{pd}=$ phelloderm .

Fig. 3. (Right) Immunolabeling of an extensin epitope in potato parallel sections. Toluidine blue $\mathrm{O}$ stained immature $(\mathbf{A})$ and mature $(\mathbf{B})$ periderm. LM1 labeling of (C) immature and (D) mature periderm for an extensin epitope. Note the increase in labeling of phellogen radial walls (indicated by arrowheads) in mature periderm. $\mathrm{Bar}=30 \mu \mathrm{m}, \mathrm{pm}=$ phellem, $\mathrm{pg}=$ phellogen, $\mathrm{pd}=$ phelloderm .
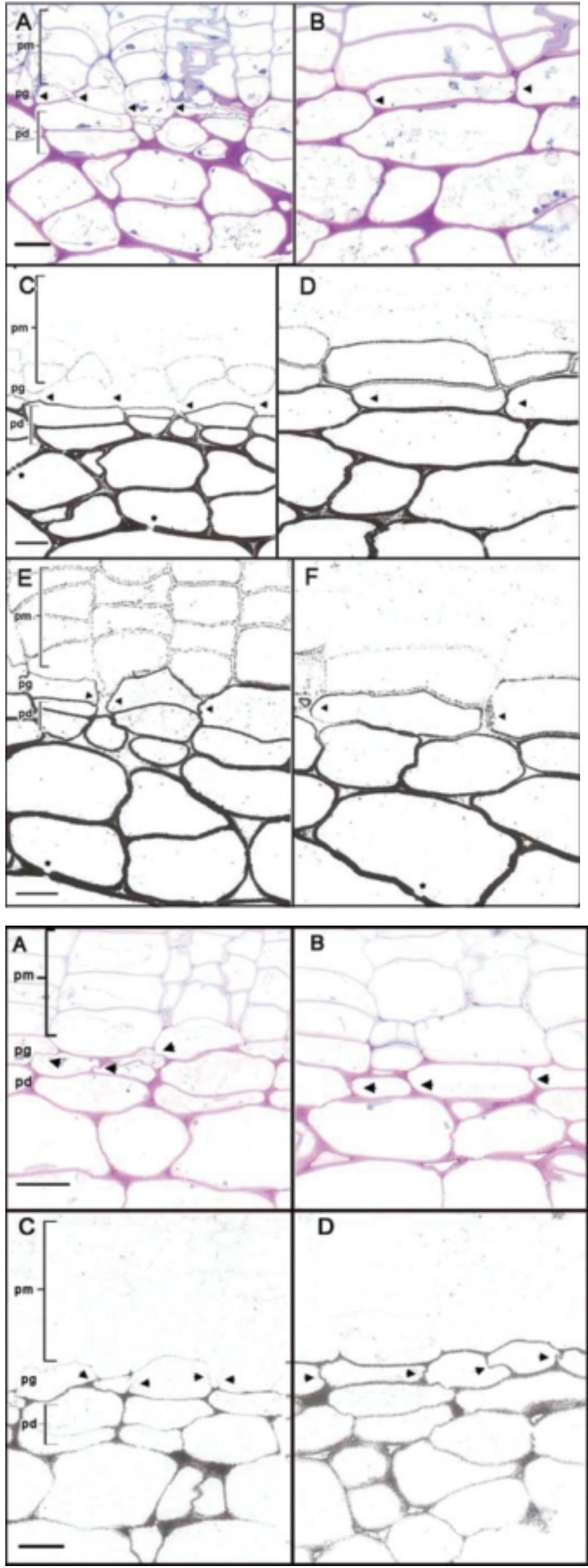
dividing cells in mung bean (Vigna radiata L.) hypocotyl tend to have highly methylated pectins and a low cation exchange capacity. Mature inactive cells have walls with sparsely methylated pectin and a high cation exchange capacity, both of which favor calcium cross-linking (Goldberg et al., 1989).

The monoclonal antibody LM5 recognizes a $(1,4)-\beta$-galactan tetrasaccharide epitope found in RG-I (Jones et al., 1997). LM5 binds to, and abundantly labels, polysaccharides which contain $(1,4)$ - $\beta$-galactosyl residues, but only sparsely labels polygalacturonic acid and locust bean gum (Jones et al., 1997). Although LM5 labeling was abundant in phelloderm cell walls, labeling was diminished in the three-way cell junctions and middle lamella between cells. This general pattern has been reported in tomato (Lycopersicon esculentum L.) pericarp (Jones et al., 1997), pea (Pisum sativum L.) cotyledons (McCartney et al., 2000), leek (Allium ampeloprasum L.) root cap cells (Willats et al., 2000b), flax (Linum usitatissimum L. ) fibers (Andeme-Onzighi et al., 2000) and flax roots (Vicre et al., 1998). Our results with potato periderm cells are consistent with recent published results that show LM5 poorly labels the three-way cell junctions and middle lamella of potato tuber cortical and perimedullary parenchyma cells (Bush and McCann, 1999; McCann et al., 2001; Oomen et al., 2002). Our results are the first to show that LM5 labels the parenchyma cells of the phelloderm as well as the cortical parenchyma interior to the periderm. These data indicate that RG-I galactan epitopes are less abundant in the middle lamella and three-way junctions of parenchyma cells, where unesterified HG tends to dominate (Knox et al., 1990; Marty et al., 1995). The diminished labeling of short segments of cortical parenchyma cell walls likely represents areas where plasmodesmata have aggregated forming pit fields, as was reported earlier for perimedullary parenchyma cells by Bush and McCann (1999). A similar pattern was reported by Orfila and Knox (2000) in tomato fruit pericarp cell walls, in which unlabeled segments were identified as pit fields.

Except for the most interior layer of phellem cells in mature periderm, LM5 labeling of phellem cell walls was very sparse, or nonexistent. This finding is consistent with results published that indicate LM5 does not label lignified cell walls in aspen (Populus tremula L.) cambial derivatives (Ermel et al., 2000) and suberized cells in potato tuber periderm (Bush and McCann, 1999).

Although LM5 labeled phellogen radial and tangential cell walls sparsely if at all in immature periderm, labeling of the thickened phellogen cell walls of mature periderm was much more abundant, implying an increase in either galactan side chains on RG-I already present, or galactan-rich RG-I in these walls upon meristematic inactivation. These data indicate that the presence of the galactan epitope in phellogen walls was temporally consistent with both HG epitopes recognized by JIM5 and JIM7. A lack of labeling for $(1,4)-\beta$-galactan in the cell walls of meristematically active cells has been reported in some other systems. Labeling with LM5 in flax root (Vicre et al., 1998) and carrot (Daucus carota L. var. sativa Hoffm.) root (Willats et al., 1999) was most prominent in cells of the root cap, while labeling was absent from the walls of meristematically active cells. LM5 did not label meristematic cells of the shoot apex in Asclepias speciosa Torr. lactifers, although it did label the walls of mature cells (Serpe et al., 2001). In developing potato stolons, LM5 was least abundant in the meristematically active cells of the stolon tip (Bush et al., 2001). The increase in the $(1,4)-\beta$-galactan epitope recognized by LM5 in the walls of inactive phellogen cells may contribute to the strengthening of these walls. This conclusion is supported by the report that cell walls of mature pea cotyledons enriched with $(1,4)-\beta$-galactan were twice as firm as cell walls of less mature cotyledons that were not enriched with this epitope (McCartney et al., 2000).

Monoclonal antibody LM6 recognizes a linear pentasaccharide of (1,5)- $\alpha$-L-arabinan found in RG-I and does not recognize rhamnogalacturonan II, arabinogalactan, extensin, or potato lectin (Willats et al., 1998). LM6 labeling of phelloderm cell walls was excluded from three-way cell junctions, which is consistent with published results of LM6 labeling of pea cotyledons (McCartney et al., 2000; Willats et al., 2000b), flax fibers (Andeme-Onzighi et al., 2000), and potato tuber parenchyma (Bush and McCann, 1999; Oomen et al., 2002). Although LM6 labeled phellogen cell walls, labeling was not noticeably different between phellogen cell walls of immature and mature periderm, indicating that the $(1,5)-\alpha$-L-arabinan epitope did not change during meristematic inactivation of the phellogen. These results indicate that the LM6 epitope is regulated independently of the LM5 epitope, as well as both $\mathrm{HG}$ epitopes, during periderm maturation. As was found with LM5, labeling of cortical parenchyma walls with LM6 was reduced in short segments, probably representing pit fields. Unlike LM6 labeling reported by Bush and McCann (1999), our results show LM6 labeling of suberized phellem walls was sparse in immature periderm, and almost nonexistent in mature periderm.

Very little research has been done on the localization of extensin in the potato tuber. Immunolocalization studies utilizing a polyclonal antibody showed that extensin in potato stem was prominent in vascular tissue, but was present in other tissues as well (Li and Showalter, 1996).

LM1 is specific for HRGPs and preferentially binds to extensin (Smallwood et al., 1995). LM1 does not bind to arabinogalactan proteins and binds with only low affinity to solanaceous lectins (Smallwood et al., 1995). Our results show that LM1 epitopes are particularly abundant at three-way cell junctions between phelloderm cells and between cortical parenchyma cells but are absent from the phellem, which follows the pattern set by JIM5. The striking contrast in LM1 labeling of phellogen radial walls before and after periderm maturation implies that HRGPs of the extensin family increase dramatically in these walls upon meristematic inactivation of the phellogen. These data indicate that the extensin epitope is regulated in a similar manner to the JIM5 HG epitope during periderm maturation. Previously published reports have shown that extensin and pectin may be closely associated in some plant cell walls (Qi et al., 1995; Swords and Staehelin, 1993). In addition, tobacco (Nicotiana tabacum L.) suspension cells adapted to cellulose-inhibitor compounds produced cellulose-free walls made of pectin and extensin (Sabba et al., 1999), indicating that pectin and extensin together can assume the structural roles typically carried out by cellulose.

Extensin monomers can become cross-linked and insolubilzed in the cell wall by the reactions catalyzed by specific peroxidases, probably by the formation of isodityrosine (Cooper and Varner, 1983; Fry, 1982) or di-isodityrosine (Brady et al., 1996) linkages. There is evidence that cross-linking of extensin can occur quickly in response to wounding (Magliano and Casal, 1998), or pathogen attack (Bradley et al., 1992; Jackson et al., 2001). Extensin can also accumulate in walls of mature cells and in walls that require special reinforcement, such as in vascular tissue (Tiré et al., 1994). It is not possible to determine, however, how much of the extensin in the mature periderm is cross-linked, because LM1 binding does not appear to be affected by cross-linking (J.P. Knox, personal communication).

We have shown that the walls of the three cell types of potato 
periderm label differentially for both pectin and extensin epitopes. While the phelloderm labels equally well for all of the epitopes tested, most of the phellem only labels abundantly for the HG epitope recognized by JIM7 and is lacking in the HG epitope recognized by JIM5, as well as the RG-I and extensin epitopes. Most significantly, labeling of the phellogen layer varied between immature and mature periderm. Cell walls of meristematically active phellogen were lacking in $(1,4)$ - $\beta$-galactan and extensin epitopes, as well as those for HG. Upon maturation of the periderm and resistance to excoriation, labeling for all of these epitopes increased dramatically in phellogen cell walls. These results imply that an increase in the presence of $\mathrm{HG}, \mathrm{RG}-\mathrm{I}$, and extensin polymers in these walls coincide with meristematic inactivation and periderm maturation. $\mathrm{HG}$ would be expected to form calcium pectate and extensin would be expected to become cross-linked in phellogen walls to provide increased strength and reinforcement once meristematic activity is terminated. The $(1,4)$ - $\beta$-galactan epitope recognized by LM5 in phellogen walls at the end of periderm maturation may also be involved in the strengthening of these walls. In contrast, the (1,5)- $\alpha$-L-arabinan epitope recognized by LM6 is present in phellogen walls before and after periderm maturation, and is apparently not associated with periderm maturation or the thickening of phellogen walls upon meristematic inactivation. A summary of the reactions of all three periderm cell types in immature and mature periderm to the antibodies used in this study is provided in Table 1 . These results also demonstrate that the tuber periderm model provides a novel means of studying changes in cell wall architecture elicited by the irreversible termination of meristematic activity in a lateral meristem.

\section{Literature Cited}

Andème-Onzighi, C., R. Girault, I. His, C. Morvan, and A. Driouich. 2000. Immunocytochemical characterization of early-developing flax fiber cell walls. Protoplasma 213:235-245.

Artschwager, E. 1924. Studies on the potato tuber. J. Agr. Res. 27:809-835.

Bradley, D.J., P. Kjellbom, and C.J. Lamb. 1992. Elicitor- and woundinduced oxidative cross-linking of a proline-rich plant cell wall protein: a novel, rapid defense response. Cell 70:21-30.

Brady, J.D., H. Sadler, and S.C. Fry. 1996. Di-isodityrosine, a novel tetrameric derivative of tyrosine in plant cell wall proteins: A new potential cross-link. Biochem. J. 315:323-327.

Bush, M.S., M. Marry, I.M. Huxham, M.C. Jarvis, and M.C. McCann. 2001. Developmental regulation of pectic epitopes during potato tuberisation. Planta 213:869-880.

Bush, M.S. and M.C. McCann. 1999. Pectic epitopes are differentially distributed in the cell walls of potato (Solanum tuberosum) tubers. Physiol. Plant. 107:201-213.

Cassab, G.I. 1998. Plant cell wall proteins. Annu. Rev. Plant Physiol. Plant Mol. Biol. 49:281-309.

Clausen, M.D., W.G.T. Willats, and J.P. Knox. 2003. Synthetic methyl hexagalacturonate haptan inhibitors of anti-homogalacturonan monoclonal antibodies LM7, JIM5 and JIM7. Carbohydrate Res. 338:1797-1800.

Cooper, J.B., J.A. Chen, G.-J. van Holst, and J.E. Varner. 1987. Hydroxyproline-rich glycoproteins of plant cell walls. Trends Biochem. Sci. 12:24-27.

Cooper J.B. and J.E. Varner. 1983. Insolubilization of hydroxyproline-rich cell wall glycoprotein in aerated carrot root slices. Biochem. Biophys. Res. Comm. 112:161-167.

Ermel, F.F., M.L. Follet-Gueye, C. Cibert, B. Vian, C. Morvan, A.-M. Catesson, and R. Goldberg. 2000. Differential localization of arabinan
Table 1. Summary of immunolocalization responses for targeted cell wall polymers in immature and mature potato tuber periderm cells.

\begin{tabular}{|c|c|c|c|c|}
\hline \multirow{2}{*}{$\begin{array}{l}\text { Antibody } \\
\text { [target] }\end{array}$} & \multirow{2}{*}{$\begin{array}{l}\text { Periderm } \\
\text { maturity }\end{array}$} & \multicolumn{3}{|c|}{ Periderm cells and localization ${ }^{\mathrm{z}}$} \\
\hline & & Phellem & Phellogen & Phelloderm \\
\hline \multirow{2}{*}{$\begin{array}{c}\text { JIM5 } \\
\text { [unesterified } \\
\text { homogalacturonan] }\end{array}$} & Immature & $-/+*$ & - & + \\
\hline & Mature & $-/+*$ & + & + \\
\hline \multirow{2}{*}{$\begin{array}{c}\text { JIM7 } \\
\text { [homogalacturonan] }\end{array}$} & Immature & $+*$ & - & + \\
\hline & Mature & $+*$ & + & + \\
\hline \multirow{2}{*}{$\begin{array}{c}\text { LM5 } \\
{[(1,4)-\beta \text {-galactan }]}\end{array}$} & Immature & - & - & $+*$ \\
\hline & Mature & $-/+*$ & $+*$ & $+*$ \\
\hline \multirow{2}{*}{$\begin{array}{c}\text { LM6 } \\
{[(1,5)-\alpha-L-\text {-arabinan }]}\end{array}$} & Immature & - & $+*$ & $+*$ \\
\hline & Mature & - & $+*$ & $+*$ \\
\hline \multirow{2}{*}{$\begin{array}{c}\text { LM1 } \\
\text { [extensin] }\end{array}$} & Immature & - & - & + \\
\hline & Mature & - & + & + \\
\hline
\end{tabular}

Periderm localization symbols: $(-)=$ sparse or no labeling; $(-/+)=$ mixed labeling; $(+)=$ abundant labeling; $(*)$ middle lamella not labeled or labeled sparsely.

and galactan side chains of rhamnogalacturonan 1 in cambial derivatives. Planta 210:732-740.

Fry, S.C. 1982. Isodityrosine, a new cross-linking amino acid from plant cell-wall glycoprotein. Biochem. J. 204:449-455.

Goldberg, R., P. Devillers, R. Prat, C. Morvan, V. Michon, and C. Hervé du Penhoat. 1989. Control of cell wall plasticity. Relationship to pectin properties, p. 312-323. In: N.G. Lewis and M.G. Paice (eds.). Plant cell wall polymers-Biogenesis and biodegradation. Amer. Chem. Soc., Washington, D.C.

Goldberg, R., C. Morvan, A. Jauneau, and M.C. Jarvis. 1996. Methylesterification, de-esterification and gelation of pectins in the primary cell wall, p. 151-172. In: J. Visser and A.G.J. Voragen (eds.). Pectins and pectinases. Elsevier Science, Amsterdam.

Jackson, P.A., C.I.R. Galinha, C.S. Pereira, A. Fortunato, N.C. Soares, S.B.Q.Amancio, and C.P.P. Ricardo. 2001. Rapid deposition of extensin during the elicitation of grapevine callus cultures is specifically catalyzed by a 40-kilodalton peroxidase. Plant Physiol. 127:1065-1076.

Jones, L., G.B. Seymour, and J.P. Knox. 1997. Localization of pectic galactan in tomato cell walls using a monoclonal antibody specific to $(1,4)-\beta$-D-galactan. Plant Physiol. 113:1405-1412.

Knox, J.P., P.J. Linstead, J. King, C. Cooper, and K. Roberts. 1990. Pectin esterification is spatially regulated both within cell walls and between developing tissues of root apices. Planta 181:512-521.

Li, S. and A.M. Showalter. 1996. Immunolocalization of extensin and potato tuber lectin in carrot, tomato and potato. Physiol. Plant. 97:708-718.

Lulai, E.C. 2001. Tuber periderm and disease resistance, p. 3-6. In: W.R. Stevenson, R. Loria, G.D. Franc, and D.P. Weingartner (eds.). Compendium of potato diseases. APS Press, St. Paul, Minn.

Lulai, E.C. 2002. The roles of phellem (skin) tensile-related fractures and phellogen shear-related fractures in susceptibility to tuber-skinning injury and skin-set development. Amer. J. Potato Res. 79:241-248.

Lulai, E.C and T.P. Freeman. 2001. The importance of phellogen cells and their structural characteristics in susceptibility and resistance to excoriation of potato tuber (Solanum tuberosum L.) during periderm maturation. Ann. Bot. 88:555-561.

Lulai, E.C. and W.C. Morgan. 1992. Histochemical probing of potato periderm with neutral red: A sensitive cytofluorochrome for the hydro- 
phobic domain of suberin. Biotechnic Histochemistry 67:185-195.

Magliano, T.M.A. and J.J. Casal. 1998. In vitro cross-linking of extensin precursors by mustard extracellular isoforms of peroxidase that respond either to phytochrome or to wounding. J. Expt. Bot. 49:1491-1499.

Marty, P., R. Goldberg, M. Liberman, B. Vian, Y. Bertheau, and B. Jouan. 1995. Composition and localization of pectic polymers in the stems of two Solanum tuberosum genotypes. Plant Physiol. Biochem. 33:409-417.

McCann, M.C., M. Bush, D. Milioni, P. Sado, N.J. Stacey, G. Catchpole, M. Defernez, C. Carpita, H. Hofte, P. Ulvskov, R.H. Wilson, and K. Roberts. 2001.Approaches to understanding the functional architecture of the plant cell wall. Phytochemistry 57:811-821.

McCartney, L., A.P. Ormerod, M.J. Gidley, and J.P. Knox. 2000. Temporal and spatial regulation of pectic (1-4)-beta-D-galactan in cell walls of developing pea cotyledons: implications for mechanical properties. Plant J. 22:105-113.

Obro, J., J. Harholt, H.V. Scheller, C. Orfila. 2004. Rhamnogalacturonan I in Solanum tuberosum tubers contains complex arabinogalactan structures. Phytochemistry 65:1429-1438.

Oomen, R., C.H.L. Doeswijk-Voragen, M.S. Bush, J.-P. Vincken, B. Borkhardt, L.A.M. van den Broek, J. Cosar, P. Ulvskov, A.G.J. Voragen, M.C. McCann, and R.G. Visser. 2002. In muro fragmentation of the rhamnogalacturonan I backbone in potato (Solanum tuberosum L.) results in a reduction and altered location of the galactan and arabinan side-chains and abnormal periderm development. Plant J. 30:403-413.

Orfila, C. and J.P. Knox. 2000. Spatial regulation of pectic polysaccharides in relation to pit fields in cell walls of tomato fruit pericarp. Plant Physiol. 122:775-781.

Peterson, R.L. and W.G. Barker. 1979. Early tuber development from explanted stolon nodes of Solanum tuberosum var. Kennebec. Bot. Gaz. 140:398-406.

Qi, X., B.X. Behrens, P.R. West, and A.J. Mort. 1995. Solubilization and partial characterization of extensin fragments from cell walls of cotton suspension cultures: Evidence for a covalent cross-link between extension and pectin. Plant Physiol. 108:1691-1701.

Ridley, B.L., M.A. O’Neill, and D.A. Mohnen. 2001. Pectins: Structure, biosynthesis, and oligogalacturonide-related signaling. Phytochemistry 57:929-967.

Sabba, R.P., N.A. Durso, and K.C. Vaughn. 1999. Structural and cytochemical characterization of dichlobenil-habituated BY-2 tobacco cells. Intl. J. Plant Sci. 160:275-290.

Sabba, R.P. and E.C. Lulai. 2002. Histological analysis of the maturation of native and wound periderm in potato (Solanum tuberosum L.) tuber. Ann. Bot. 90:1-10.
Sabba, R.P. and E.C. Lulai. 2004. Immunological comparison of native and wound periderm maturation in potato tuber. Amer. J. Potato Res. 81:119-124.

Schindler, T.M. 1998. The new view of the primary cell wall. Zeitschrift Fur Pflanzenernahrung und Bodenkunde 161:499-508.

Serpe, M.D., A.J. Muir, and A.M. Keidel. 2001. Localization of cell wall polysaccharides in nonarticulated laticifers of Asclepias speciosa Torr. Protoplasma 216:215-226.

Smallwood, M., H. Martin, and J.P. Knox. 1995. An epitope of rice threonine- and hydroxyproline-rich glycoprotein is common to cell wall and hydrophobic plasma-membrane glycoproteins. Planta 196:510-522

Swords, K.M.M. and L.A. Staehelin. 1993. Complementary immunolocalization patterns of cell wall hydroxyproline-rich glycoproteins studied with the use of antibodies directed against different carbohydrate residues. Plant Physiol. 102:891-901.

Thakur, B.R., K.S. Rakesh, and K.H. Avtar. 1997. Chemistry and uses of pectin-A review. Critical Rev. Food Sci. Nutr. 37:47-73.

Tiré, C., R. De Rycke, M. De Loose, D. Inzé, M. Van Montagu, and G. Engler. 1994. Extensin gene expression is induced by mechanical stimuli leading to local cell wall strengthening in Nicotiana plumbaginifolia. Planta 195:175-181.

Vicre, M., A. Jauneau, J.P. Knox, and A. Driouich. 1998. Immunolocalization of beta- $(1 \rightarrow 4)$ and beta- $(1 \rightarrow 6)$-D-galactan epitopes in the cell wall and Golgi stacks of developing flax root tissues. Protoplasma 203:26-34.

Willats, W.G.T., G. Limberg, H.C. Buchholt, G.J. van Alebeek, J. Benen, T. Christensen, J. Visser, A. Voragen, J.D. Mikkelsen, and J.P. Knox. 2000a. Analysis of pectin structure part 2-Analysis of pectic epitopes recognized by hybridoma and phage display monoclonal antibodies using defined oligosaccharides, polysaccharides, and enzymatic degradation. Carbohydrate Res. 327:309-320.

Willats, W.G.T., S.E. Marcus, and J.P. Knox. 1998. Generation of a monoclonal antibody specific to (1-5)- $\alpha$-arabinan. Carbohydrate Res. 308:149-152.

Willats, W.G.T., L. McCartney, W. Mackie, and J.P. Knox. 2001. Pectin: cell biology and prospects for functional analysis. Plant Mol. Biol. 47:9-21.

Willats, W.G.T., C.G. Steele-King, S.E. Marcus, and J.P. Knox. 1999. Side chains of pectic polysaccharides are regulated in relation to cell proliferation and cell differentiation. Plant J. 20:619-628.

Willats, W.G.T., C.G. Steele-King, L. McCartney, C. Orfila, S.E. Marcus, and J.P. Knox. 2000b. Making and using antibody probes to study plant cell walls. Plant Physiol. Biochem. 38:27-36.

Wilson, L.G. and J.C. Fry. 1986. Extensin-A major cell wall glycoprotein. Plant Cell Environ. 9:239-260. 